\title{
Road Safety Study during Construction Work of an at Grade Intersection Converting it to a Flyover
}

\author{
A. Sala \\ Research Scholar \\ EU-Asia Road Safety Centre of Excellence (RoSCoE) \\ Prince of Songkla University, Hat Yai 90112, Songkla, Thailand \\ E-mail: s.weerajak@gmail.com
}

Abstract: A flyover was constructed for solving the traffic problems, to improve the traffic flow at an intersection, to reduce the delays and accidents. 25 traffic accidents occurred during the construction work. This study will point out the issues that might be the cause of all these accidents around the construction area and in the conclusion the data of road safety evaluation (accident costs) will be shown.

Keywords: road safety, flyover construction, accident cost

\section{Introduction}

To solve the traffic problems at intersections on bypass roads such as traffic volume, accidents (as shown in Figure 1) and delays etc., the flyover is one of the tools to solve these problems. Normally in Thailand, the flyover is constructed at junctions on bypass roads near big cities.

A flyover is the special bridge constructed above existing at-grade intersections. It allows for the free flow of traffic on different levels, with the main goal of for reducing traffic conflicts, whereas the intersection is still the same old signal controlled.

Hat Yai City is an important center of the transport sector and economic growth of the southern provinces, particularly, the transport of passengers and goods in the three borderland southern provinces and between Thailand and neighboring countries like Malaysia and Singapore. Definitely, the transport of passengers and goods are efficiently provided and facilitated by the transport sector; Songkhla has a total of $750.748 \mathrm{~km}$. of route length, 22 train stations and Hat Yai International Airport $(9 \mathrm{~km}$ from the downtown of Hat Yai city) can support 1,505,906 passengers in 2010.

In 2009 the Government hired the Department of Highway (DOH) to construct a flyover at Sanambinnai Intersection. It was constructed on a length $1+325.570$ kilometers above the old intersection by an investment of 249,597,672.5 THB. There were about 12,500 vehicles per day $(\mathrm{DOH}, 2008)$ travelling as usual despite the construction and 25 accidents occurred (DOH, 2011) during construction work. This 
study will point out the issues that might be the cause of all these accidents around the construction area and in the conclusion the data of road safety evaluation (accident costs) will be shown.

\section{Study area details}

The study area consists of Highway route number 43 and Highway route number 4135 in Songkhla province. The intersection was an at-grade one before a flyover was recently constructed at station $24+489.400 \mathrm{~km}$ (a schematic map of Hat Yai city is shown in Figure 2), and 967.00 meters of length of bridge and 540 days of construction time (increased to 929 days due to the natural disaster).

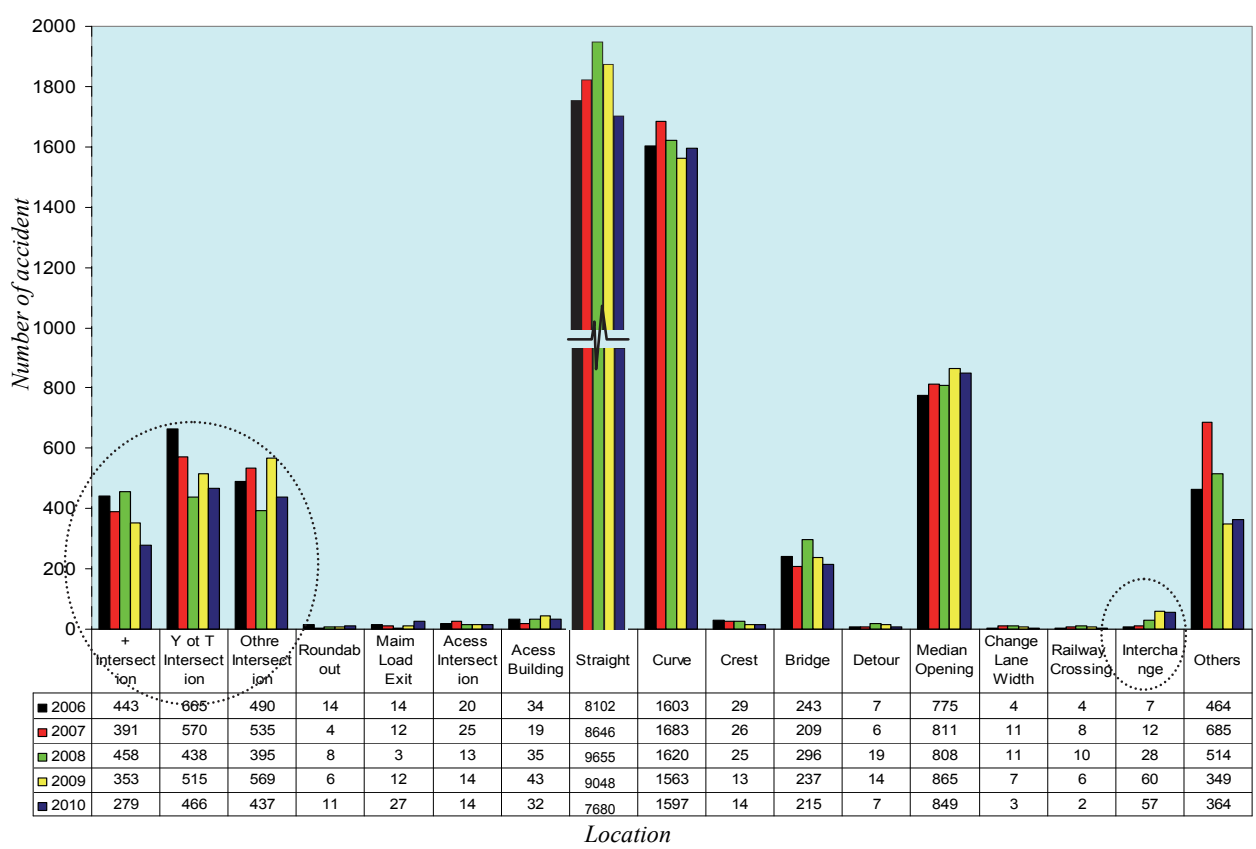

Figure 1. Traffic accidents on highways by accident location in Thailand [4]

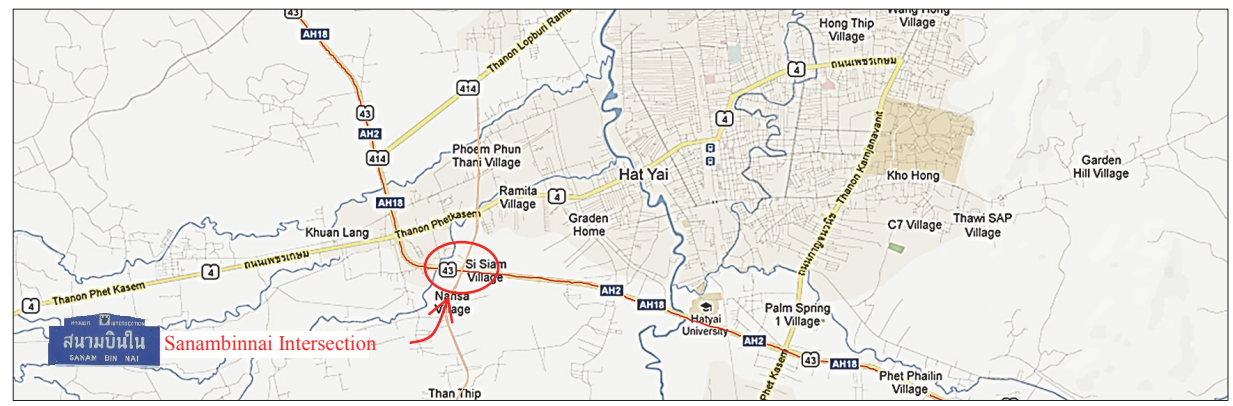

Figure 2. A schematic map of Hat Yai city with the study area marked 
This intersection is situated at $6^{\circ} 59^{\prime} 13.00^{\prime \prime} \mathrm{N}$ latitude and $100^{\circ} 25^{\prime} 42.93$ " E longitude and the physical data of the two important roads are;

Highway route number 43

- The distance is $104.268 \mathrm{~km}$, link road from Phatthalung province along the road to Pattani province,

- AADT at station $8+317 \mathrm{~km}: 15,824$ vehicles/ day and lane separated by an island, and

- 2 lanes/ direction, 3.5 meter/ lane, outer and inner shoulders of the road are $1.0 \&$ 0.5 meter, respectively.

Highway route number 4135

- The distance is $9.965 \mathrm{~km}$, link road from the Sanambinnok intersection along the road to Hat Yai International Airport.

- AADT at station 1+300 km: 18,323 vehicles/ day and lanes separated by yellow markings, and

- 2 lanes/ direction, 3.5 meter/ lane, outer and inner shoulders of the road are 1.0 \& 0.5 meters respectively.

The signal control at the intersection was fixed time type, 4 phases, 2 programs a day; the first program has a cycle length of 244 seconds, it was operating from 06:00 am to 12:00 pm and the second program was flashing amber, it was used from 00:00 am to 06:00 am, the data as shown in Figure 3.

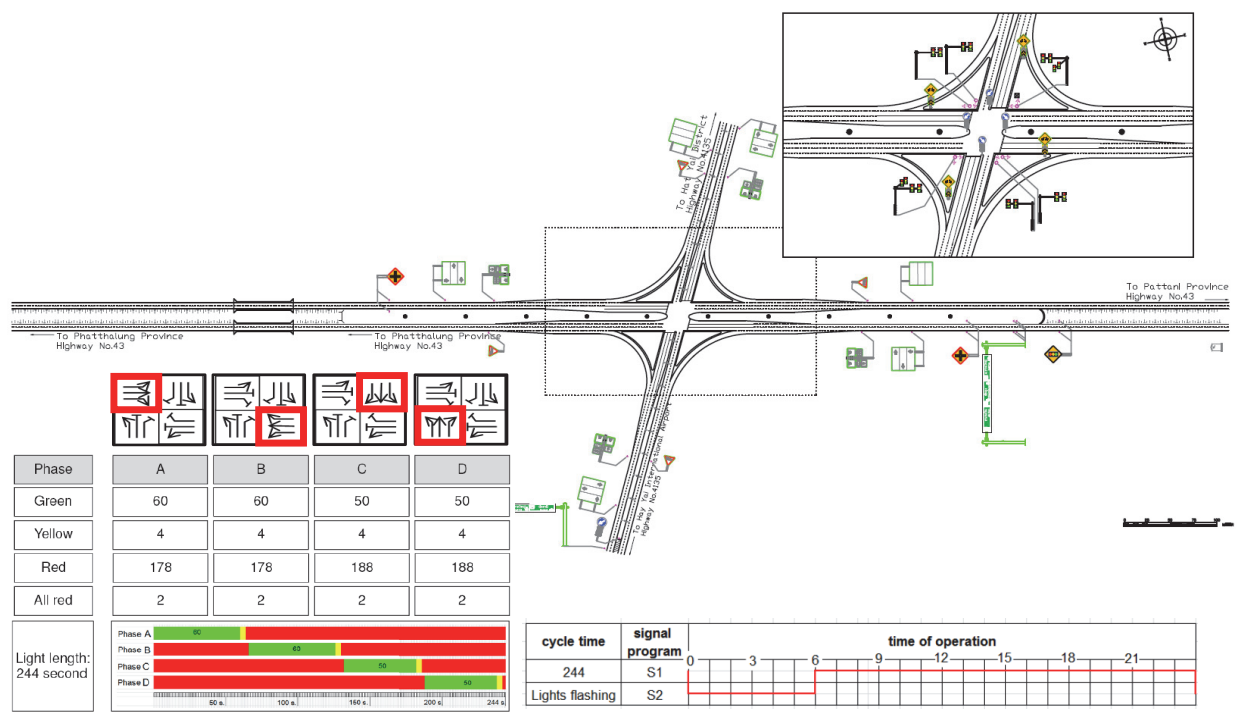

Figure 3. Physical data of highway route no 43 and highway route no 4135 (before construction) and the signal control program 


\section{Methodology}

This study will point out the traffic problems during the construction work between the construction zone and road users since the first to the last day of this project.

\subsection{Stages of construction}

During the stages of construction, there were 3 main steps for protecting the road users travelling through this intersection (shown in the figure 4). The project owner planned and installed traffic signs, flashing beacons and other informational signs.

In Zone 1 the river bridge was constructed, the road was extended to 3 lanes and the pillar for a special bridge was constructed on the road island. Concrete blocks and traffic cones were installed for dividing road users from the work zone, but sometimes it was divided explicitly, but sometimes it was not installed to protect and temporary Uturn was constructed by soil material near the river bridge.

In Zone 2 the pillar of the special bridge was constructed, this process was implemented simultaneously with zone 1 and the management process was similar to that of zone 1.

Zone 3 was the last area to work on, after all pillars of the special bridge were constructed in zone 1 and 2 . The traffic signals were operating like the old signals (fixed time type, 4 phases, 2 programs a day, but changed the cycle time of the first program from 244 to 254 seconds, it was operating from 06:00 am to 12:00 pm and the second program (flashing amber), was used from 00:00 am to 06:00 am.

24 accidents occurred in the zone no 1 and zone no 2 and all accidents were registered.

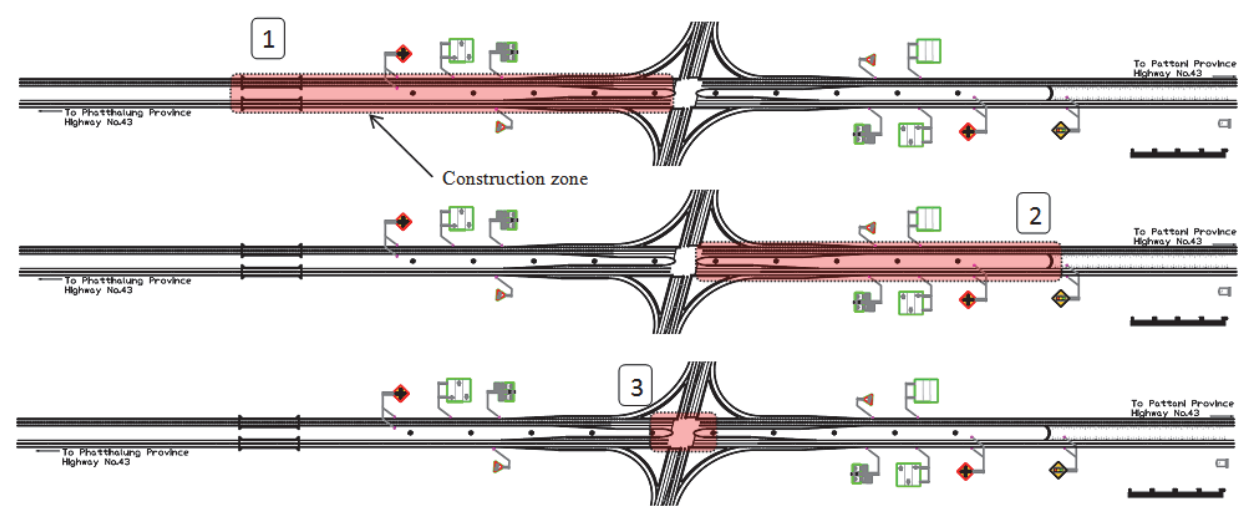

Figure 4. Stage during construction management

\subsection{Road Safety Audit}

Road Safety Audit under construction stage covers the following items [9];

* Traffic Management, 
* Traffic signs and road markings,

* Traffic signals,

* Pedestrians and bicycles,

* Road surface, and

* Other issues.

Field audit was conducted during 3 periods: day-time, night-time and raining. The following issues were found during on-site audits:

* Traffic Managements

The picture of traffic management issues are shown in Figure 5

- The temporary traffic signs were installed at inappropriate locations,

- Did not have the staff to protect 2 zones,

- Auditor found only one of the speed limit signs $(50 \mathrm{~km} / \mathrm{h})$; it was installed on the HW route 43 before entry to intersection 300 meters,

- Concrete blocks did not cover the construction zone, they did not protect the road users and construction zones, on the contrary, they raised problems for the road users because of their different sizes and, installed at inappropriate locations,

- Street lights according to the guideline of road lane direction were not turned on every night, and

- Road sections and construction zones were not divided clearly, so vehicles could enter and cross construction zones.

* Traffic signs and Road markings

The pictures of traffic signs and road marking issues are shown in Figure 6

- The installation of temporary traffic signs was not stable, not enough and insufficient,

- Traffic signs were not reflective at night and some traffic signs were damaged,

- Background (brown) and text (black) in traffic signs could not be seen clearly,

- There were traffic signs with different characteristics, and

- Road markings at intersection could not be seen clearly.

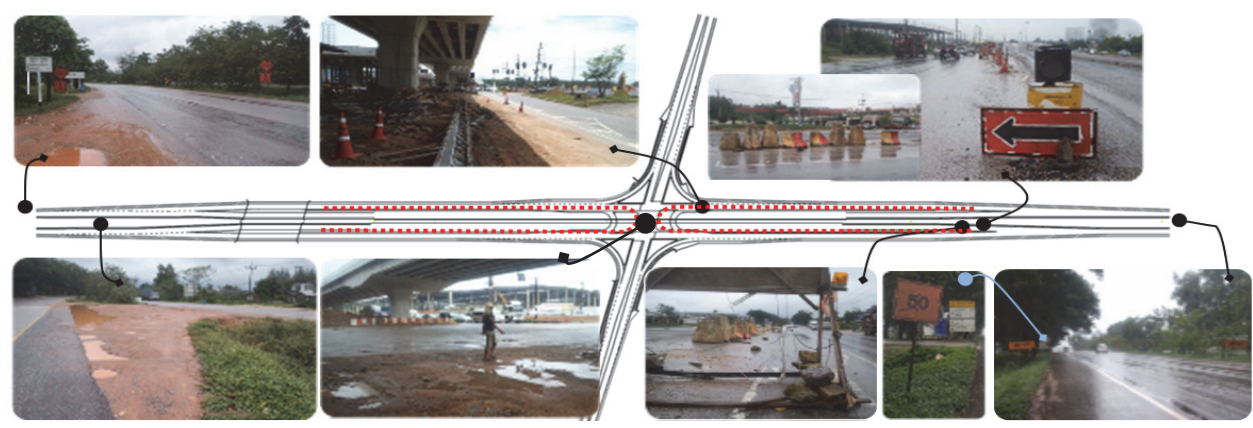

Figure 5. Traffic management issues 
* Traffic lights

- The traffic signal control was using 4 phases, it consisted of 2 programs a day; the first program had a cycle of 254 seconds, it was operating from 06:00 am to 12:00 pm. During peak time (7:45-8:00 am) average queue length of the 4 legs were 48 vehicles (PCU). The second program was flashing amber, it was used from 00:00 am to 06:00 am.

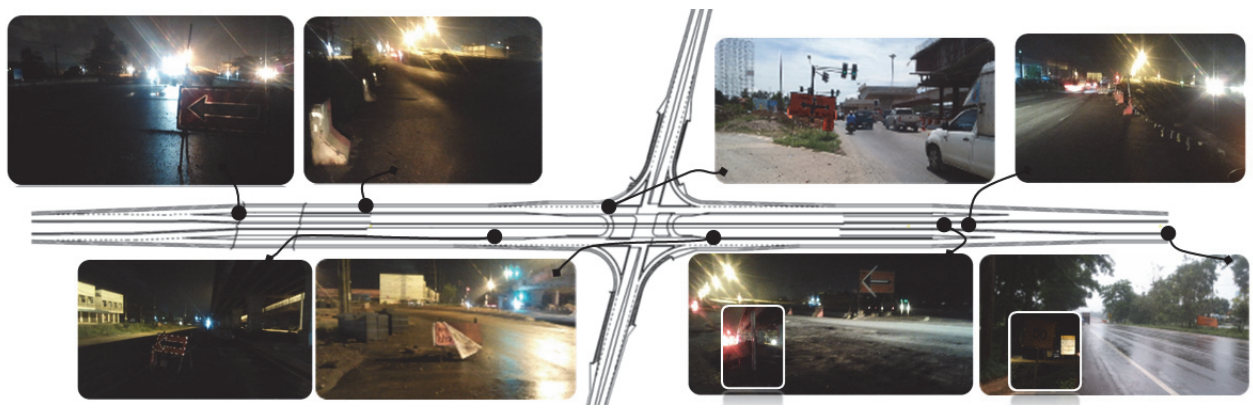

Figure 6. Traffic signs and road marking issues

* Pedestrians and bicycles

The pictures of pedestrians and bicycle issues are shown in Figure 7

- There were no stopping lines for motorcycles and bicycles at the intersection,

- There were scraps on the shoulder of the road, the bicycle cannot bike on this area, and

- There were loose aggregates that reduce skid resistance around this construction zone.

* Road Surface

The pictures of road surface issues are shown in Figure 7

- Road surface was not smooth and bumpy,

- There was water covering the surface of road after rain, and

- Mud mound, soil, and raw aggregates were found on the sidewalk and on the shoulder.

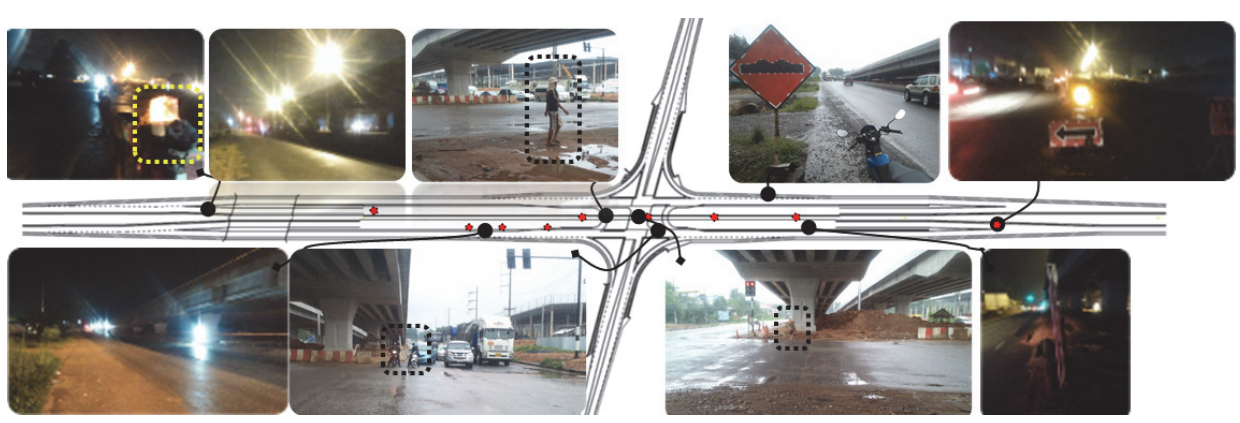

Figure 7. Pedestrians, bicycles and road surface issues 
* Other issues

The pictures of other issues are shown in Figure 8

- There were no energy absorbing devices at the edge of the river bridge,

- There were no guardrails or concrete blocks between the road surface and roadside area to prevent the vehicles from falling down the road, and

- There were fixed rigid objects near the road surface.

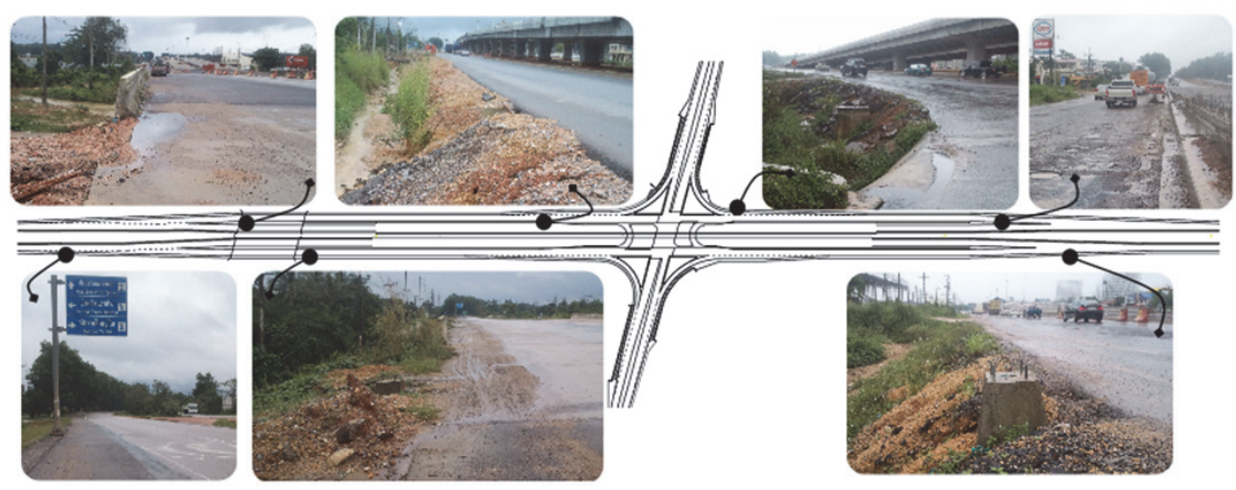

Figure 8. Other issues

\subsection{Accident statistics}

As for accident statistics during construction work, this study collected data from the Department of Highways (DOH) and from the project owner. During the 929 days of construction, 52 accidents were found, of which 25 were sufficiently documented. Data cover such as spot of accidents, collision diagram, number of casualties, property damage only and cause of the accident.

\section{Results and discussions}

This intersection was improved by an investment costing about 250 million THB. The intersection was audited according to the road safety manual. In accidents statistic the top three causes of accidents were rear-end in the same lane (6 cases), hit with fixed solid objects (3 cases) and vehicle hits vehicle at intersection (3 cases) respectively. Vehicle types of the top three of the accidents are first one is car (13 vehicles), second is pick up (11 vehicles) and third is trailer (8 vehicles) respectively. On 15th April 2012 the new flyover was opened, under the flyover it is still the old junction controlled by traffic signals.

All of the 25 accidents where the data on the spot of accident and time of the accident are consistent with the time of management of each zone are shown in Figure 10. Accident costs were calculated as follows; 


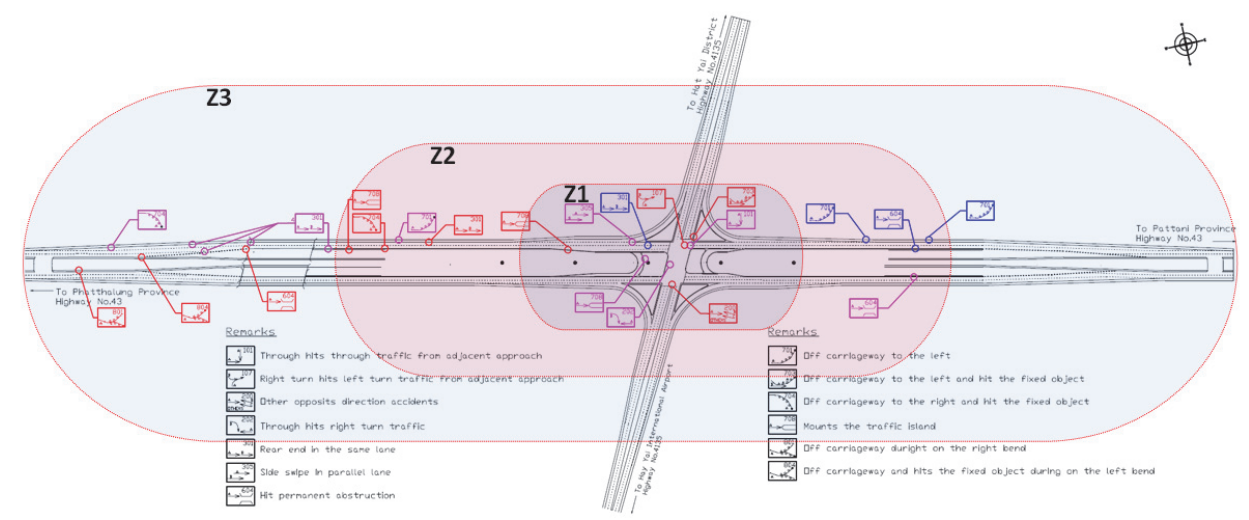

Accident: 25 times/ 929 days (Z1: 9, Z2: 9, Z3: 7)

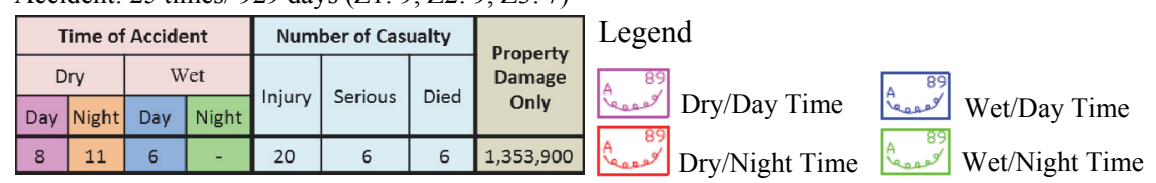

Figure 10. Spot of accident at intersection area and collision diagram

\section{Accident costs (AC)}

Used to describe the combined effect of number and severity of the accidents [8]

Annual average accident cost ACa [€/year]:

$$
A C a(F+S I+L I+P D O)=\frac{A(F) \times M C A(F)+A(S I) \times M C A(S I)+A(L I) \times M C A(L I)+A(P D O) \times M C A(P O D)}{t}
$$

where: $\mathrm{A}$ is number of accidents (acci),

MCA is the mean cost per accident ( $€ /$ acci) as shown in table 1 , and $t$ is the period of time under review (year).

$A C a(F+S I+L I+P D O)=\frac{(6 \times 5,178,000)+(6 \times 151,500)+(20 \times 29,750)+1,353,900}{(929 / 365)}=13,329,336$ Baht 
Table 1. The mean cost per accident for various severities [5]

\begin{tabular}{|l|c|c|c|}
\hline Severity & $\begin{array}{c}\text { Thailand } \\
\text { (Million Baht) }\end{array}$ & $\begin{array}{c}\text { Bangkok } \\
\text { (Million Baht) }\end{array}$ & $\begin{array}{c}\text { Other Provinces } \\
\text { (Million Baht) }\end{array}$ \\
\hline Fatality & $5.062-5.956$ & $10.561-12.413$ & $4.757-5.599$ \\
\hline Disability & $5.114-6.910$ & $11.611-13.934$ & $5.608-6.729$ \\
\hline Serious Injury & $0.158-0.164$ & $0.328-0.337$ & $0.148-0.155$ \\
\hline Slight Injury & $0.0386-0.0389$ & $0.1731-0.1733$ & $0.0297-0.0298$ \\
\hline Property Damage Only & 0.052 & 0.164 & 0.039 \\
\hline
\end{tabular}

\section{Conclusion}

According to Road Safety Audits under construction stage, the issues of on-site audits can be summarized as follows;

- The number of "temporary traffic signs" was not enough, no maintenance during construction, installed at improper locations, not reflective at night and made by hand (different styles and dimensions),

- "Concrete Blocks" not covered the construction zone, they did not protect the road users and construction zones, on the opposite, they caused problems for the road users because of their different sizes and inappropriate locations,

- "Street-lights" were not installed consecutively and not turned on every night,

- "Road surfaces" were not smooth but bumpy, the mud mound on the shoulder of the road made always a problem when raining, and

- There were no guard rails or concrete blocks between the road surface and roadside area to prevent the vehicles from falling down the road, although there were fixed rigid objects near the road.

Accident statistics during construction work is a reflection of construction management; there were 52 accidents (this 52 accidents were collected by 3 agencies) of 929 days. Because the sufficiency of accident data from 3 agencies is different, this study only used accidents data from Department of Highway (25 accidents). The cost of these 25 accidents occurred is equivalent to 13,329,336 THB in 2011.

\section{Recommendations}

In terms of Road Safety, the recommendations of this study are the followings;

- The "temporary traffic signs" should use standard signs, installed at appropriate and sufficient locations "Road surface" should not have pothole and soil aggregates on the road surface.

- "Street-lights" should be installed consecutively and turned on every night

- "Concrete Blocks" should be installed at appropriate locations, they should clearly show which are road user, roadside and construction zones. They should be installed covering the project construction area without gaps.

- Traffic signal control during construction and open road should follow traffic volumes of each leg and period of the day, and 
- $\quad$ Field works should have traffic engineering staff for controlling or checking the possibility of accidents.

\section{References}

[1] Accident rates of 10 countries in Asia, Asian Development Bank, 2008

[2] Road Safety Audit, Austroads Project No. RSS.SS.C.008, Austroads Incorporated, Sydney, NSW, Australia. 2002

[3] Accident Statistical Report of HAIMS 2011, http://haims.doh.co.th, visited at 04/04/2013

[4] Traffic Accident on National Highways in 2011, Bureau of Highways Safety, Ministry of Transport, Thailand, 2011

[5] Accident cost rate in Thailand of 2011, Bureau of Highways Safety, Ministry of Transport, Thailand, 2012

[6] Definition of Road Safety Audit, Federal Highway Administration, Washington DC, USA, 2011

[7] Proctor, S.: Road Safety Audit Guidelines, The Chartered Institution of Highways \& Transportation, www.iht.org, 2002

[8] Gatti, G., Polidori, C., Galvez, I., Mallschützke, K., Jorna, R., de Leur, M.V., Dietze, M., Ebersbach, D., Lippold, C., Schlag, B., Weller, G., Wyczynski, A., Iman, F., Aydin, C.: Safety Handbook for Secondary Roads, Final report in EC Sixth Framework Programme, Contract No. 506184, 2005

[9] Taneerananon, P., Tanaboriboon, Y., Srisakda, L.: Thailand Road Safety Audit Manual, Department of Civil Engineering, Prince of Songkla University, Thailand, 2009

[10] Vesper, A.: General Aspects of Road Safety-Transfer of Knowledge, BauhausUniversität Weimar, European Commission, Germany, 2011 